\title{
Teaching Medical Advances in a Time of Crisis: A Human Microbiome Data Interpretation E-Learning Elective for Medical Students
}

\author{
Jorge L. Cervantes: Texas Tech University Health Sciences Center El Paso, Paul L Foster School of Medicine, \\ Department of Medical Education, El Paso, TX, USA.
}

\begin{abstract}
Medical schools were upended by the COVID-19 pandemic resulting in suspension of all in-person educational activities, and leaving clinical clerkships on hold. Emerging medical advances need to be integrated in undergraduate medical curriculum as evidence continues to evolve regarding their clinical application. Here, we describe an innovative distance- learning elective course developed to keep fourth year medical students abreast of important scientific advances. Within each module, each successive entry introduced concepts with increasing complexity and included up-to-date literature material to help in the learning progression. Students' overall satisfaction was high, as the elective helped them gain personal confidence, improved their medical and intellectual skills, increased their curiosity in medical science, and allowed them to analyze scientific literature they did not understand before.
\end{abstract}

Key words: Human microbiome, Distance learning, Scientific advances, Undergraduate medical education.

\section{Introduction}

The ongoing pandemic presents practical and logistical challenges and concerns for medical student activities, including the risk of students potentially spreading the virus when asymptomatic, or that they may acquire the virus in the course of training (Rose, 2020). In March, the Association of American Medical Colleges (AAMC) recommended suspension of "medical student participation in any activities that involved patient contact" to U.S. medical schools (Goldenberg, Hersh, Wilkins, \& Schwartz, 2020). Medical schools around the world made the decision to suspend all clinical clerkships in the face of the coronavirus disease 2019 (COVID-19) pandemic (Goldenberg et al., 2020). The need to prepare future physicians has never been as focused as it is now in the setting of a global emergency. The profound effects of COVID-19 may forever change how future physicians are educated (Rose, 2020).

The replacement of in-person training with online equivalents is an obvious necessity at this time. The cancellation of clerkships is a serious issue that students and medical schools must now face (Ferrel \& Ryan, 2020).

Scientific medical advances are not sufficiently covered in undergraduate medical curricula, Eden, Johnson, Gottesman, Bottinger, and Abul-Husn (2016); Plunkett-Rondeau, Hyland, and Dasgupta (2015). Furthermore, many physicians feel unprepared to apply scientific advances to their medical practice (Christensen et al., 2016; Standford Medicine, 2020).

A virtual curriculum and novel teaching methods were needed to fulfill curricular requirements. Here, a comprehensive virtual clerkship elective on the interpretation of human microbiome data is presented. 


\section{Material and Methods}

\subsection{Fourth Year Elective}

A 2-week distance-learning clerkship elective was designed to accommodate fourth year medical students who had not yet completed the required clerkship elective. The design included two self-paced modules, one per week, which included sequential didactic activities to progressively help the student to inferentially understand human microbiome data in medical literature. During the two-week elective course students were tasked to research and then respond to questions related to human microbiome data. Although relevant literature for every question was provided, students were free to research other sources on their own. Student performance was assessed via their responses to each module, and via the quality of a final Powerpoint presentation. Students had complete freedom in the design, content, and flow of their final presentation, as tailoring it to their upcoming field of specialization could be beneficial in future projects they may choose to undertake. Feedback from students was collected using an online survey Table 1, with responses in a Likertstyle with $1=$ Strongly disagree; $2=$ Disagree; $3=$ Neutral; 4= Agree; 5= Strongly agree.

Week 1

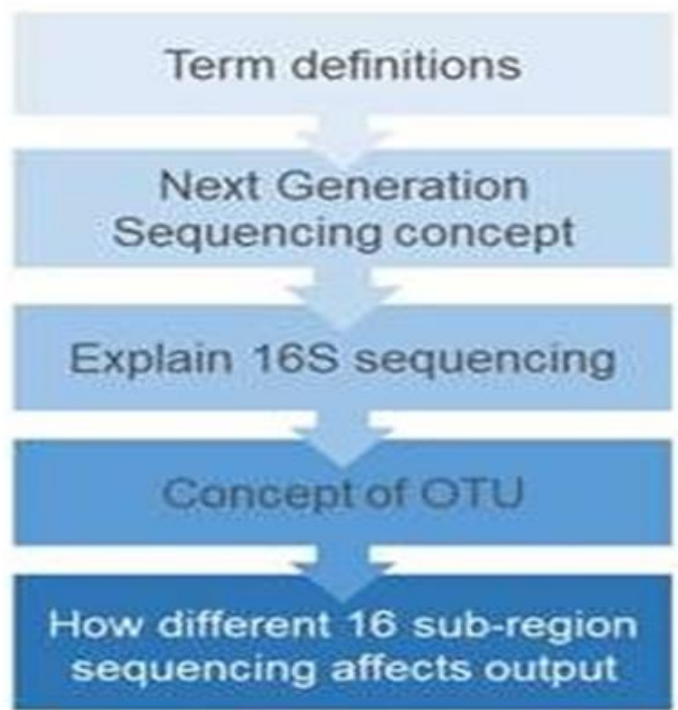

Week 2

How microbiota data is presented

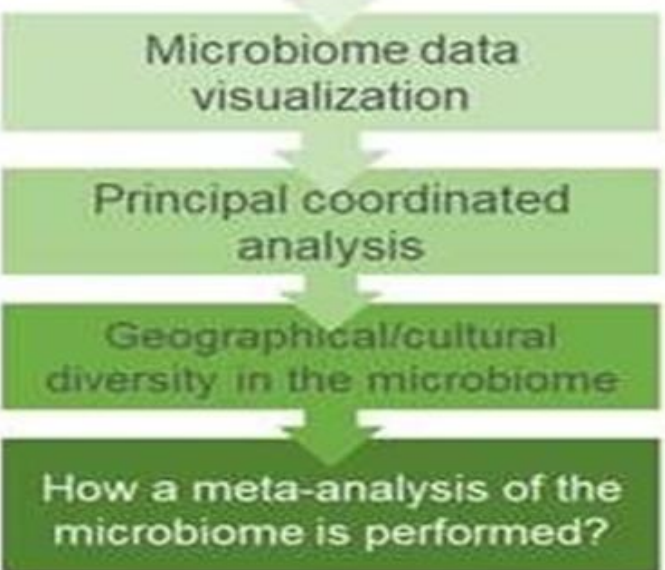

Figure-1. Elective weekly modules showing the sequence of topics; Relevant literature was provided for every entry.

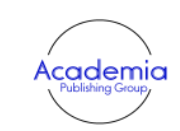

International Journal of Educational Studies

Volume 4, Issue 2, pp. 60-64

2021

DOI: $10.53935 / 2641-533 x . v 4 i 2.157$

Funding: This study received no specific

financial support.

Acknowledgement: Special thanks to Dr. BoYoung Hong for helping editing the manuscript. Article History:

Received: 16 August 2021

Revised: 5 October 2021

Accepted: 8 November 2021

Published: 25 November 2021

(C) 2021 by the authors; licensee Academic Publishing Group

\section{RESULTS FROM THE SURVEY}

"strongly disagree =Disagree = Neutral =Agree | Strongly agree

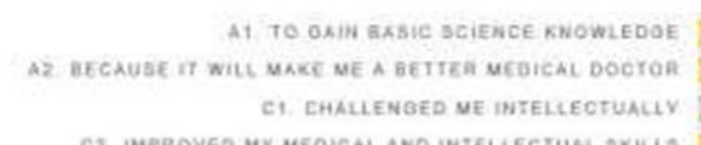

C2 IMPROVES MY MEOICAL ANO WTELLECTUAL AKULL

F1. RDVANCED WY CAREER

Q2. IMCREASE UY PERSORAL CONFIDENCE

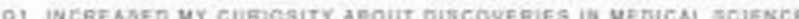

Q2. WILL GIVE NE A CAMEER AOVANTAOE

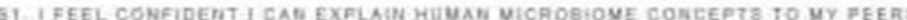

S2 I FEEL CONFIDENT TO EXPLAIN HQUAN VICROEIOME CONCEPTS TO UY PATIENTS

93. EHHANCED MY NMOWLFDOE OF SCIENOE

B4. ALLOWEO ME. TO ANALYZE SCIENTIFIC LITERATURE I DIDNT UNDEดSTAND

BS. $T$ DAHED EXPERIENCE THAT WILI HELF ME WN THE FUTURE WITH BCIENCE

DS OAVE VE A BETTER QRABP OF HOW TO WRITE A RESEARCH PAPEF

WAS A OOOD ANO EFFEOTIVE WAY OF LEABNINO THE TOPICA OE TME ELECTIVE

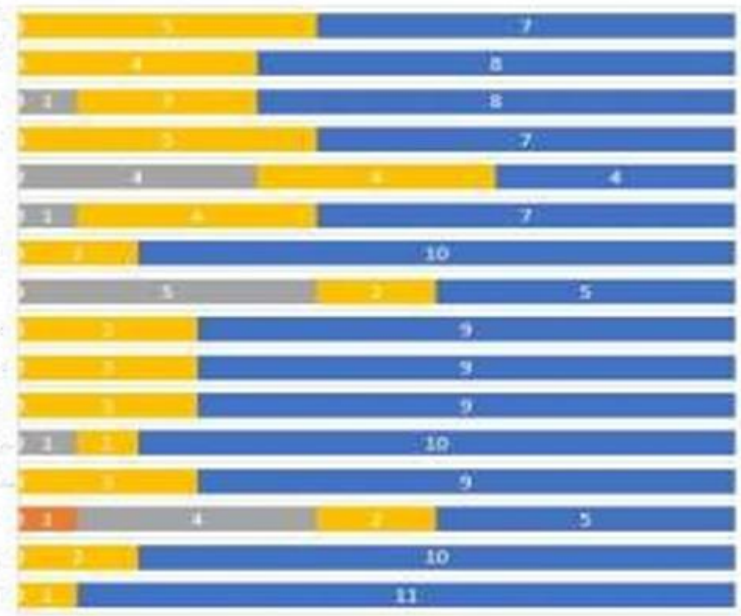

Figure-2. Results from the survey; Responses were provided in a Likert-style with $1=$ Strongly disagree; $2=$ Disagree; $3=$ Neutral; $4=$ Agree; 5= Strongly agree 


\section{Results}

Students stated that the elective helped them build a framework on how to approach reading microbiome literature. Additionally, they indicated that it helped them to close gaps about the fundamentals of microbiome data. Furthermore, it gave them the opportunity to build a presentation using what they learned in the elective, and apply it to the field of microbiome research Several students stated that they plan to conduct microbiome research in the future during residency Table 2. Students overall satisfaction was high. From the survey, all the participants agreed that the elective helped them gain basic science knowledge, it will make them better doctors, and made them feel confident to explain human microbiome concepts to their peers and patients Figure 2. Students, entirely, also recognized that the elective helped them gain personal confidence, improve their medical and intellectual skills, increased their curiosity in medical science, and allowed them to analyze scientific literature they did not understand before.

Table-1. Survey questionnaire.

I decided to carry out this elective:

A1. To gain basic science knowledge

A2. Because it will make me a better medical doctor

Performing this elective:

C1. Challenged me intellectually

C2. Improved my medical and intellectual skills

P1. Advanced my career.

P2. Increase my personal confidence

Understanding the human microbiome

Q1. Increased my curiosity about discoveries in medical science

Q2. Will give me a career advantage.

After completing this elective:

S1. I feel confident I can explain human microbiome concepts to my peers

S2. I feel confident to explain human microbiome concepts to my patients

S3. Enhanced my knowledge of science.

S4. Allowed me to analyze scientific literature I didn't understand before.

S5. I gained experience that will help me in the future with science projects and activities.

S6. Gave me a better grasp of how to write a research paper.

The online remote format of the elective:

$\mathrm{X} 1$. Was a good and effective way of learning the topics of the elective

X2. Provided a comfortable way to develop the course at my own pace

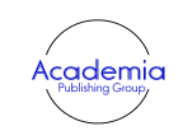

International Journal of Educational Studies

Volume 4, Issue 2, pp. 60-64

2021

DOI: $10.53935 / 2641-533 x . v 4 i 2.157$

Funding: This study received no specific

financial support.

Acknowledgement: Special thanks to Dr. BoYoung Hong for helping editing the manuscript. Article History:

Received: 16 August 2021

Revised: 5 October 2021

Accepted: 8 Nover 2021

Accepted. 8 November 2021

(C) 2021 by the authors; licensee Academic

Publishing Group
Table-2. Students' comments

\section{The most important thing I gained from this elective was}

The elective helped me build a frame work on how to approach reading microbiome literature. Additionally, it helped me close gaps about the fundamentals of microbiome data. Furthermore, it gave me the opportunity to build a presentation using what I learned in the elective and apply

it to the field of microbiome research I plan to conduct in the future during residency. The faculty was readily available for questions!

Learning about microbiome data - how it is collected, analyzed, and presented

An introductory understanding to Microbiome concepts and how data is organized, interpreted, and presented.

Gained insight into 16S Sequencing and Next Generation Sequencing \& exposure to human microbiota research

Learning the basics about microbiome

A better understanding of the microbiome, how to interpret data pertaining to it and its many uses

Being able to translate science to direct patient care

The approaches to generate and analyze microbiome data

Learning in depth about the different technologies used to sequence bacterial DNA. It is something we read about in class but never actually understand how it is done! Reading about next generation sequencing was actually fun for me.

Learning about the microbiome related to the field I will be going into.

Learning about how the microbiome is different among individuals, especially those with certain medical conditions. Learning how to analyze microbiomes. 


\section{Discussion}

The Paul L. Foster School of Medicine offers a highly integrated curriculum across the 4 years of undergraduate medical education (UME). Cutting-edge medical scientific discoveries are commonly underrepresented in UME and pose a significant challenge in medical education as scientific information evolves at a very fast pace (Plunkett-Rondeau et al., 2015), challenging outdated educational materials and textbooks (Rubanovich, Cheung, Mandel, \& Bloss, 2018).

Medical schools were upended by the COVID-19 pandemic, resulting in suspension of all in-person educational activities, and leaving clinical clerkships on hold (Durfee et al., 2020). Persistence and adaptability during this time of challenge are now necessary for medical students to demonstrate a set of skills which they would had previously acquired through in person activities (Ferrel \& Ryan, 2020). Implementing technology to help resolve these issues is a unique way to help students to develop important skills, such as gaining confidence to explain to peer and patients complex scientific concepts.

Here, an innovative distance-learning two-week elective course was developed to keep students abreast of important scientific advances. Within each module, each successive entry introduces concepts with increasing complexity and include up-to-date literature material to help in the learning progression Figure 1.

Online education courses for clerkship medical students had already been proposed, even before the pandemic (Holland, Grinberg, \& Tabby, 2014), sometimes combining the online learning activities with real patient care (Wiecha, Vanderschmidt, \& Schilling, 2002). Use of e-learning programs as an addition to conventional teaching has shown to lead to improvement in basic knowledge and reasoning (Fransen, Martens, Nagtzaam, \& Heeneman, 2018). A completely virtual clerkship elective can be a successful educational experience for medical students during a time when remote learning is required. Personal connections between faculty and students can be challenging in a virtual course (Durfee et al., 2020), however, the availability of various education video platform have made these interactions smooth and effective.

\section{Conclusions}

Judging from the survey responses, the goal of this activity, which is to promote core competencies regarding scientific frontiers in medicine, increasing confidence and empowering medical students to utilize scientific advances in their careers, was achieved. Not only it enhanced their knowledge and understanding of science and technologies, but provided them with confidence to explain these concepts to peers and patients, something that they will keep applying throughout their career.

Changes in the delivery of an elective, in this instance forced by the global pandemic, have the potential to be drastic turning points in the career progression of medical students. It will be necessary in the future to evaluate and study the full impact of these changes in medical education.

\section{References}

Christensen, K. D., Vassy, J. L., Jamal, L., Lehmann, L. S., Slashinski, M. J., Perry, D. L., . . Murray, M. F. (2016). Are physicians prepared for whole genome sequencing? A qualitative analysis. Clinical Genetics, 89(2), 228-234. Available at: https://doi.org/10.1111/cge.12626.

Durfee, S. M., Goldenson, R. P., Gill, R. R., Rincon, S. P., Flower, E., \& Avery, L. L. (2020). Medical student education roadblock due to COVID-19: Virtual radiology core clerkship to the rescue. Academic Radiology, 27(10), 1461-1466. Available at: https://doi.org/10.1016/j.acra.2020.07.020.

Eden, C., Johnson, K. W., Gottesman, O., Bottinger, E. P., \& Abul-Husn, N. S. (2016). Medical student preparedness for an era of personalized medicine: Findings from one US medical school. Personalized Medicine, 13(2), 129-141. Available at: https://doi.org/10.2217/pme.15.58.

International Journal of Educational Studies

Volume 4, Issue 2, pp. 60-64

2021

DOI: 10.53935/2641-533x.v4i2.157

Funding: This study received no specific financial support.

Acknowledgement: Special thanks to Dr. BoYoung Hong for helping editing the manuscript. Article History:

Received: 16 August 2021

Revised: 5 October 2021

Accepted. 8 November 2021

Published: 25 November 2021

Publish: 25 Novernber 2021 licensee Academic

Publishing Group

$$
\text { | } 63
$$

Ferrel, M. N., \& Ryan, J. J. (2020). The impact of COVID-19 on medical education. Cureus, 12(3), e7492.

Fransen, F., Martens, H., Nagtzaam, I., \& Heeneman, S. (2018). Use of e-learning in clinical clerkships: Effects on acquisition of dermatological knowledge and learning processes. International Journal of Medical Education, 9, 11-17. Available at: http://doi:10.5116/ijme.5a47.8ab0.

Goldenberg, M. N., Hersh, D. C., Wilkins, K. M., \& Schwartz, M. L. (2020). Suspending medical student clerkships due to COVID19. Medical Science Educator, 30(3), 1273-1276. Available at: https://doi.org/10.1007/s40670-020-00994-1.

Holland, N. R., Grinberg, I., \& Tabby, D. (2014). A standardized online clinical education and assessment tool for neurology clerkship students assigned to multiple sites. Perspectives on Medical Education, 3(1), 41-45.

Plunkett-Rondeau, J., Hyland, K., \& Dasgupta, S. (2015). Training future physicians in the era of genomic medicine: Trends in undergraduate medical genetics education. Genetics in Medicine, 17(11), 927-934. Available at: https://doi.org/10.1038/gim.2014.208. 
Rose, S. (2020). Medical student education in the time of COVID-19. Jama, 323(21), 2131-2132. Available at: https://doi.org/10.1001/jama.2020.5227.

Rubanovich, C. K., Cheung, C., Mandel, J., \& Bloss, C. S. (2018). Physician preparedness for big genomic data: A review of genomic medicine education initiatives in the United States. Human Molecular Genetics, 27(R2), R250-R258. Available at: https://doi.org/10.1093/hmg/ddy170.

Standford Medicine. (2020). Stanford medicine 2020 health trends report. The Rise of the Data-Driven Physician.

Wiecha, J. M., Vanderschmidt, H., \& Schilling, K. (2002). HEAL: An instructional design model applied to an online clerkship in family medicine. Academic Medicine: Journal of the Association of American Medical Colleges, 77(9), 925-926. Available at: https://doi.org/10.1097/00001888-200209000-00027.

\footnotetext{
International Journal of Educational Studies

Volume 4, Issue 2, pp. 60-64

2021

DOI: $10.53935 / 2641-533 x . v 4 i 2.157$

Funding: This study received no specific

financial support.

Acknowledgement: Special thanks to Dr. BoYoung Hong for helping editing the manuscript. Article History:

Received: 16 August 2021

Revised: 5 October 2021

Accepted: 8 November 2021

Published: 25 November 2021

(C) 2021 by the authors; licensee Academic

Publishing Group 